\title{
sala \\ de

\section{HABILIDADES VISUAIS: UMA VIVÊNCIA EM SALA DE AULA VIRTUAL EM TEMPO DE PANDEMIA}

\author{
VISUAL HABILITIES: a virtual classroom experience in time of pandemic \\ Prof. Dr. José Carlos Pinto Leivas \\ Universidade Franciscana de Santa Maria - UFN \\ leivasjc@ufn.edu.br
}

\begin{abstract}
Resumo: neste artigo apresenta-se uma pesquisa de cunho qualitativo, realizada no primeiro semestre de 2020, que teve o objetivo de analisar como participantes de um Grupo de Estudos e Pesquisas em Geometria exploram a visualização, a imaginação e a criatividade em atividades geométricas. Foram aplicadas três tarefas adaptadas do site Canguru Matemático, em três encontros realizados em plataforma digital, em virtude do período de isolamento social em que se encontram as atividades didáticas presenciais. Cada uma foi aplicada como fechamento dos trabalhos nos três encontros consecutivos do grupo. Após as aplicações, os dados foram coletados, via WhatsApp, sendo as justificativas enviadas a posteriori pelo mesmo instrumento. Os resultados são considerados importantes para atender ao sugerido no Working Group do PME a respeito da importância de pesquisas envolvendo Representação e Visualização, pois mostraram dificuldades com tais habilidades. Acredita-se que o experimento possa ser útil para outros profissionais envolvidos com o ensino de Geometria explorarem.
\end{abstract}

Palavras-chave: Visualização. Imaginação. Criatividade. Ensino e aprendizagem em Geometria.

\begin{abstract}
: this article presents a qualitative research, carried out in the first semester of 2020, which aimed to analyze how participants in a Group of Studies and Research in Geometry explore visualization, imagination and creativity in geometric activities. Three tasks adapted from the "Canguru Matemático" site were applied in three meetings held on a digital platform, due to the period of social isolation in which the classroom teaching activities are found. Each was applied as the closing of the works in the three consecutive meetings of the group. After applications, data were collected via WhatsApp, and after justifications were sent a by the same instrument. The results are considered important to meet what was suggested in PME Working Group about the importance of research involving Representation and Visualization, as they showed that some people, even having already completed disciplines in their initial formation, still have difficulties with such skills. We believe that the experiment may be useful for other professionals involved in the teaching of Geometry to explore.
\end{abstract}

Keywords: Visualization. Imagination. Creativity. Teaching and Learning in Geometry.

\section{INTRODUÇÃO}

Matemática, ainda nos dias de hoje, desperta reações de medo, insatisfação, frustação, dentre outras. Em pesquisa realizada por Soares, Vargas e Leivas (2020), foram investigadas as percepções de estudantes do Ensino Médio em relação à disciplina Matemática. A partir disso, concluíram que os indivíduos, ao serem solicitados a desenharem como se sentiam, o fizeram por meio de imagens que revelavam sentimentos ruins. 


\section{sala \\ de $\oplus$ em \\ aula foco}

REVISTA ELETRÔNICA

ISSN 2316-7297

Geometria é uma disciplina que merece uma atenção especial na formação inicial de professores de Matemática, de modo que os egressos possam inovar quando ingressarem no mercado de trabalho. Dessa forma, tais profissionais poderão modificar o cenário indicado há algumas décadas, ou seja, de que esse campo é abandonado, especialmente no ensino básico (PAVANELLO, 1989; MIKUSCA, 2011). Leivas (2009), em sua pesquisa de doutorado, fez um levantamento a respeito de enfoques de geometrias em geral, em cursos de formação de professores no Rio Grande do Sul, detectando existir falta de componente curricular, ainda permanecendo a ausência de abordagens como a das geometrias não euclidianas.

Pouco se percebe no cenário nacional de mudanças que contribuam para atenuar tais deficiências. Oliveira (2016), em sua dissertação de mestrado, trabalhou com um grupo de professores dos anos finais do Ensino Fundamental, em atividades que buscavam ampliar os conhecimentos desses professores sobre transformações geométricas. A autora concluiu que houve mudanças na compreensão de como ensinar Geometria, particularmente, no envolvimento de isometrias e homotetias, tema importante para desenvolver pensamento geométrico. Acredita-se que isso possa contribuir para desenvolver processos que favoreçam o ensino de Geometria.

O Grupo de Estudos e Pesquisas em Geometria- GEPGEO, liderado pelo autor do artigo desde 2016, tem se preocupado em buscar alternativas que possam contribuir para a melhoria do ensino dessa área nos diversos segmentos: Anos Iniciais, Ensino Fundamental, Médio e Superior, sendo o último voltado à formação de professores de Matemática e Pós-Graduação. Assim, busca-se materiais e metodologias que venham nessa direção. Neste momento em que a pandemia e o isolamento social se fazem presentes, o grupo se reúne virtualmente, uma vez por semana. Surgiu, pois, a ideia de realizar uma investigação que pudesse ilustrar como é possível desenvolver um experimento para a sala de aula de uma forma diferenciada do que usualmente se realiza no cotidiano. Nesse sentido, buscou-se promover inovações para as salas de aula que pudessem auxiliar no desenvolvimento de pensamento geométrico e contribuir para a mudança no cenário de abandono da Geometria.

A partir desses pressupostos, justifica-se o presente trabalho, que buscou responder à seguinte questão: como indivíduos participantes de um grupo de estudos e pesquisas em Geometria utilizam 


\section{sala \\ de $\oplus$ em \\ aula foco}

-REVISTA ELETRÔNICA

visualização para resolverem questões geométricas em aula virtual? Para tal, delineou-se o objetivo da pesquisa aqui apresentada: analisar como participantes de um grupo de estudos e pesquisas em Geometria exploram visualização, imaginação e criatividade em atividades geométricas. Na sequência, apresenta-se alguns fundamentos teóricos envolvidos nos estudos e pesquisas do grupo.

\section{CRIATIVIDADE, VISUALIZAÇÃO E IMAGINAÇÃO NO ENSINO DE GEOMETRIA}

Um dos eventos internacionais mais relevantes para a Educação Matemática é a Conference of the International Group for the Psychology of Mathematics Education - PME, no qual, na edição de 1998, foi criado o Working Group intitulado Representação e Visualização Matemática, que tem indicado a importância de realização de pesquisas nesse tema. Além da continuação da pesquisa de doutorado do autor deste artigo, também o acompanhamento de alguns trabalhos do Working Group tem norteado as pesquisas desenvolvidas pelo grupo de estudos e pesquisa em que este trabalho foi desenvolvido, o qual está ligado a um programa de pós-graduação em ensino de Ciências e Matemática na região central do Rio Grande do Sul, desde 2016.

O tema visualização, internacionalmente, vem sendo explorado há algumas décadas. Presmeg (1986, p. 298) indica que "Um método visual é aquele que envolve imagem visual, com ou sem um diagrama, como uma parte essencial do método de solução, mesmo se os métodos de raciocínio ou algébrico são ambos empregados"1. Guzmán (1997, p. 16) define visualização em Matemática como "essa forma de atuar com atenção explícita às possíveis representações". Cifuentes $(2005$, p. 58) considera que "visualizar é ser capaz de formular imagens mentais e está no início de todo o processo de abstração". Por sua vez, Leivas (2009) assim define visualização: "é um processo de formar imagens mentais, com a finalidade de construir e comunicar determinado conceito matemático, com vistas a auxiliar na resolução de problemas analíticos ou geométricos".

Os termos imagery and visualization (imaginação e visualização) se entrelaçam na literatura internacional com significados muito próximos. Para Stylianou (2001, apud Presmeg, 2006, p. 228), “O papel da imaginação visual na resolução de problemas matemáticos permanece uma questão

\footnotetext{
${ }^{1}$ As citações internacionais são de livre responsabilidade do autor.
} 


\section{sala \\ de $\oplus$ em \\ aula foco}

-REVISTA ELETRÔNICA

atual em pesquisas educacionais". Tais termos também podem se aproximar de criatividade e abstração. Segundo Hadamard (2000, p. 104), Descartes já havia dito que “[...] a imaginação será muito útil, sobretudo, quando se tiver de resolver um problema não por simples dedução, mas por várias deduções sem ligação entre si, das quais, a seguir, será preciso fazer a enumeração completa e coordenar os resultados".

Em termos de psicologia, Vygotsky (2014), ao abordar sobre imaginação e criatividade dos adolescentes, afirma a ideia direta de que imaginação e criatividade estão ligadas a um retrabalho livre de vários elementos da experiência, os quais estão combinados livremente, bem como exigem nível de liberdade interior de pensamento, ação e conhecimento. De acordo com o autor, somente aquele que dominou o pensamento em conceitos pode alcançar. A isso se associa o pensamento matemático no presente artigo. Isso indica, também, que indivíduos em uma ação continuada, já possuindo um conhecimento de conteúdos matemáticos, podem conectá-los na resolução de um problema geométrico de forma criativa, imaginativa e visual, como se propôs neste trabalho experimental de uma aula virtual. Problemas criativos envolvendo Geometria e Imaginação foram sugeridos por Conway, Gilman e Thurston (2010), dos quais alguns são abordados no grupo em outras situações, produzindo alguns recursos para o ensino.

\section{O CENÁRIO METODOLÓGICO}

A presente pesquisa foi realizada no primeiro semestre letivo de 2020, como já explicitado, em um trabalho virtual realizado por um grupo de estudos e pesquisas em Geometria, a partir da necessidade de isolamento social, em virtude da pandemia provocada pela Covid-19. Os encontros se realizaram pela plataforma Google Meet, de forma criativa, de modo a não perder a continuidade de seus estudos presenciais. Durante a realização da pesquisa o grupo estava formado por um aluno da Licenciatura em Matemática e outros estudantes de pós-graduação nessa mesma área, orientandos e ex-orientandos do autor do artigo. Dessa forma, reitera-se o afirmado por Serverino (2016) sobre os objetivos do ensino superior. Para o autor, oportunizar alternativas de realizar pesquisa, ensino e extensão, é papel mediador fundamental da universidade, pois "[...] no âmbito universitário, dada a natureza específica de seu processo, a educação superior precisa ter na pesquisa o ponto básico de apoio e sustentação de suas outras duas tarefas, o ensino e a extensão" (p. 23-24). 


\section{sala \\ de $\oplus$ em \\ aula foco}

-REVISTA ELETRONNICA

Trata-se, assim, de uma pesquisa qualitativa no sentido apontado por Serverino (2016, p. 125): “[...] com estas designações, cabe referir-se a conjuntos de metodologias, eventualmente, envolvendo diversas referências epistemológicas". Também é um estudo de caso, na medida em que o caso representativo é verificar como os indivíduos exploram visualização, imaginação e criatividade na resolução de três tarefas distintas, realizadas em momentos distintos, propiciando coleta de dados a serem analisados pelo investigador.

Por meio de slides em Power Point, as atividades foram apresentadas aos participantes do estudo ao final de cada um dos encontros, as quais nada tinham a ver com o conteúdo daquela ocasião, visto que o objetivo era mobilizar conhecimentos matemáticos pré-existentes. Os estudantes utilizariam alguns minutos para resolvê-las e encaminhá-las pelo WhatsApp ao professor, individualmente, como será descrito para cada uma das tarefas (seção 4). Lembra-se que cada um se encontrava em local distinto, não proporcionando contato entre si para a resolução.

A fim de não identificar os sujeitos participantes, os mesmos foram designados por letras: A, B, C, D, E, F e G, conforme indicado no Quadro 1, sendo utilizadas as siglas: R-realizou, NC-não compareceu. Os demais, por motivos não informados, não estavam participando neste período.

\section{Quadro 01 - Elementos participantes}

\begin{tabular}{|c|c|c|c|c|}
\hline Identificação & formação & Aula 1 & Aula 2 & Aula 3 \\
\hline A & Doutorando & $\mathbf{R}$ & $\mathbf{R}$ & $\mathbf{R}$ \\
\hline B & Doutoranda & $\mathbf{R}$ & N.C. & R \\
\hline C & Doutorando & $\mathbf{R}$ & $\mathbf{R}$ & N.C. \\
\hline D & Doutorando & $\mathbf{R}$ & $\mathbf{R}$ & $\mathbf{R}$ \\
\hline E & Doutora & $\mathbf{R}$ & N.C. & R \\
\hline F & Pós Doutora & N.C & R & R \\
\hline
\end{tabular}

Fonte: dados do autor

Na sequência, apresenta-se cada atividade e a respectiva análise a partir das respostas fornecidas pelos indivíduos Como o número de participantes foi bem reduzido, acredita-se que não seria relevante categorizá-las. 


\section{sala \\ de $\oplus$ em \\ aula foco}

REVISTA ELETRÔNICA

\section{AS ATIVIDADES E RESPECTIVAS ANÁLISES}

As atividades aqui propostas e analisadas foram adaptadas do site Canguru Matemático, de Portugal².

\section{1 - A PRIMEIRA TAREFA}

Esta primeira tarefa foi retirada do Canguru Matemático sem Fronteiras, ano 2019, proposta para a Categoria Júnior, a qual envolve alunos de 10 e 11 anos e foi adaptada para esta pesquisa. Como indicado no Quadro 01, dos sete estudantes presentes no grupo no momento, apenas um não compareceu na atividade (estudante F) por motivo de saúde. Nessa ocasião, foi apresentado o slide constante da Figura 1. Todos os demais responderam ao que fora solicitado, tendo o investigador dado cinco minutos para observarem a figura. Em seguida, pediu para a interpretarem, responderem e justificarem, encaminhando a solução, por exemplo, por meio de uma foto do que registraram.

Figura 01 -Primeira tarefa apresentada

\section{Na figura estão marcados nove quadrados geometricamente iguais.}

Relativamente aos ângulos assinalados, qual é a relação entre os ângulos $\alpha$ e $\beta$ ? Justifique

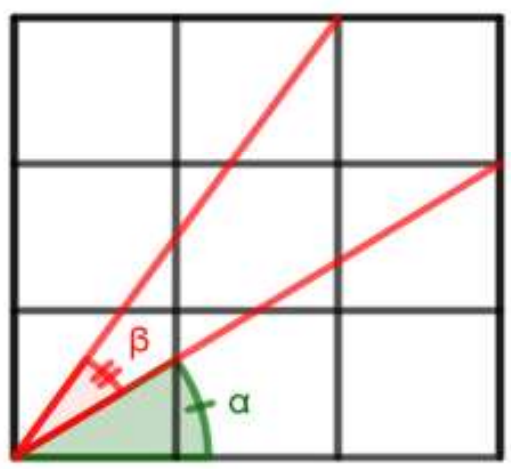

Fonte: Adaptado do Canguru Matemático de 2019.

As respostas dos indivíduos foram assim categorizadas: C- acertou e justificou corretamente; ERR errou; C*-alguma restrição; n.c. não compareceu. A partir disso, concluiu-se que apenas dois dos sete estudantes acertaram e justificaram corretamente as respostas ( $\mathrm{A}$ e $\mathrm{C}$ ), dois acertaram parcialmente (E e F) e os demais erraram.

\footnotetext{
${ }^{2}$ https://www.mat.uc.pt/canguru/
} 


\section{sala \\ de $\oplus$ em \\ aula foco}

A: acertou a relação entre as medidas dos dois ângulos e justificou corretamente pela congruência dos dois triângulos, com base no caso clássico de congruência LAL. Denominou os vértices de cada triângulo e denotou a congruência por $\triangle A B C \cong \triangle A D E$. Logo, indicou $\angle B A D=90 \circ$ e $90 \circ=2 \alpha+\beta$, concluindo que $\beta=90$ - $2 \alpha$ (Figura 02).

\section{Figura 02 -Solução apresentada pelo estudante A}

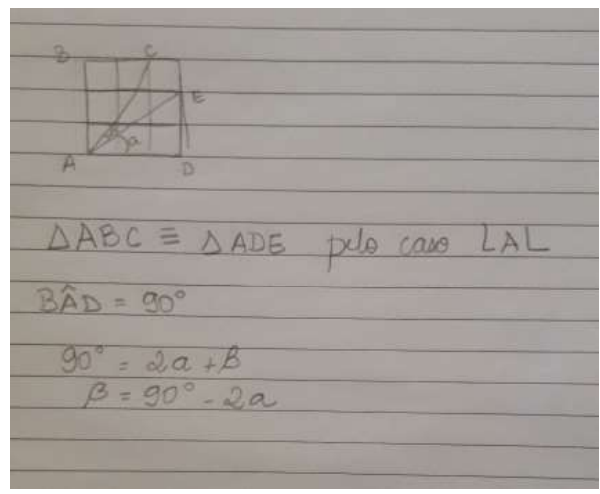

Fonte: arquivo do pesquisador

C: acertou e justificou corretamente. Ao contrário de A, usou a tangente dos ângulos $\alpha, \beta$ nos respectivos triângulos retângulos caracterizados com eles e com os catetos conhecidos. Usou a tangente $\operatorname{tg} \alpha=2 / 3$ e a da soma desses dois ângulos, obtendo e $\operatorname{tg} \beta=5 / 12$. Porém, percebeu não ter como relacionar os dois ângulos e sim suas tangentes. Partiu, então, para uma segunda forma de relacionar os ângulos. (Figura 03).

Figura 03 -Solução apresentada pelo estudante B

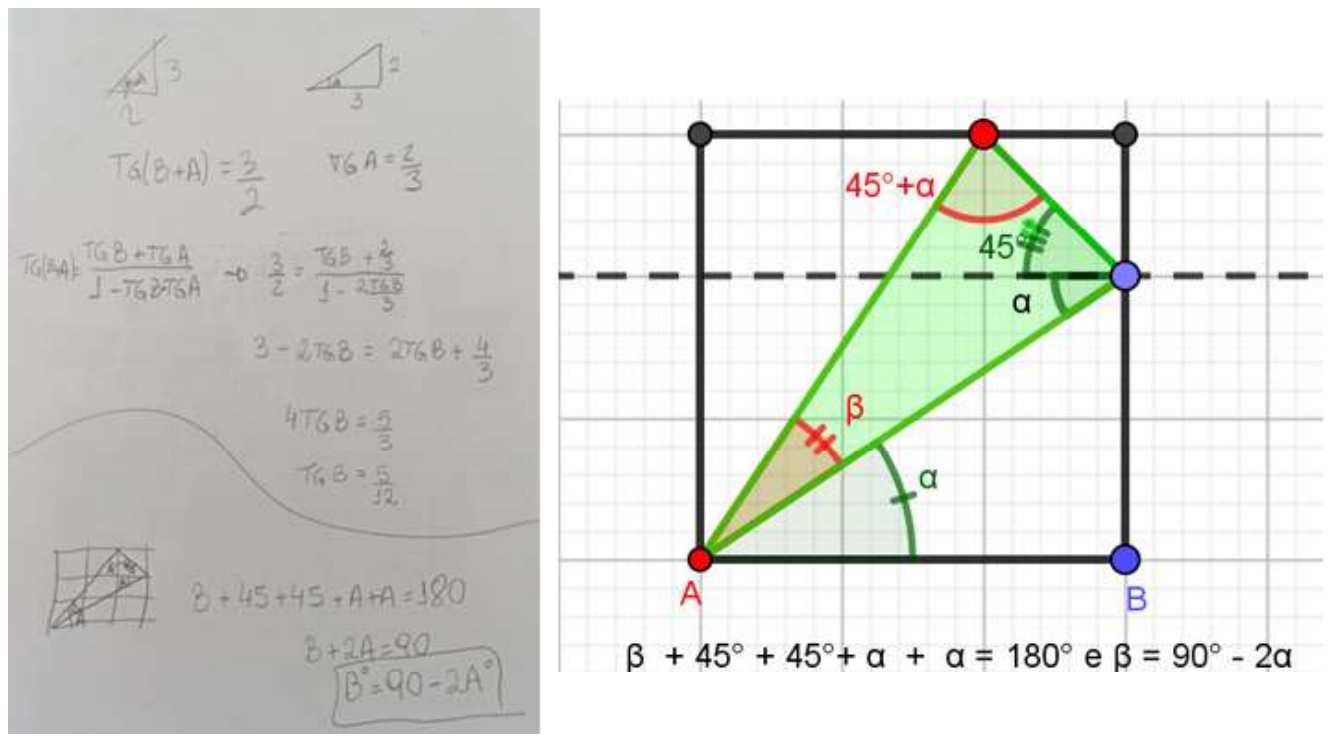

Fonte: arquivo do pesquisador 


\section{sala \\ de $\theta$ em \\ aula foco}

REVISTA ELETRÔNICA

ISSN 2316-7297

Como não houve clareza na resolução de sua reconstrução da representação para obter a resposta correta, a partir da relação $\beta+450+45 \circ+\alpha+\alpha=180$ e e, para concluir que $\beta=90 \circ-2 \alpha$, foi solicitado explicar como obtivera a relação. Assim, esclareceu ter visualizado também congruências de triângulos e relação entre ângulos alternos internos (Figura 03 à direita) para concluir que $\beta=90$ $2 \alpha$, corretamente.

E: interpretou de forma correta os dois ângulos assinalados como consecutivos, porém não chegou a uma resposta conclusiva. Usou, como $C$, a tangente de $\alpha$ e a da soma dos dois, $\beta+\alpha$, chegando a que $\alpha=\operatorname{arctg}(2 / 3)$ e $\beta=\operatorname{arctg}(5 / 12)$. Porém, não estabeleceu relação entre os dois, como foi indicado.

F: embora não tenha comparecido virtualmente na investigação, o fez posteriormente, indicando ter utilizado o procedimento de observar a figura e controlar o tempo de 5 minutos para a resposta, a qual não encaminhou.

B: errou, pois justificou errado, uma vez que considerou ângulos com medidas específicas.

D: errou por ter considerado que o ângulo $\beta$ estava sobreposto ao ângulo $\alpha$, isto é, teriam o primeiro lado na horizontal comum e o segundo lado do a entre este primeiro e o terceiro (Figura 04).

\section{Figura 04 -Solução apresentada pelo estudante D}

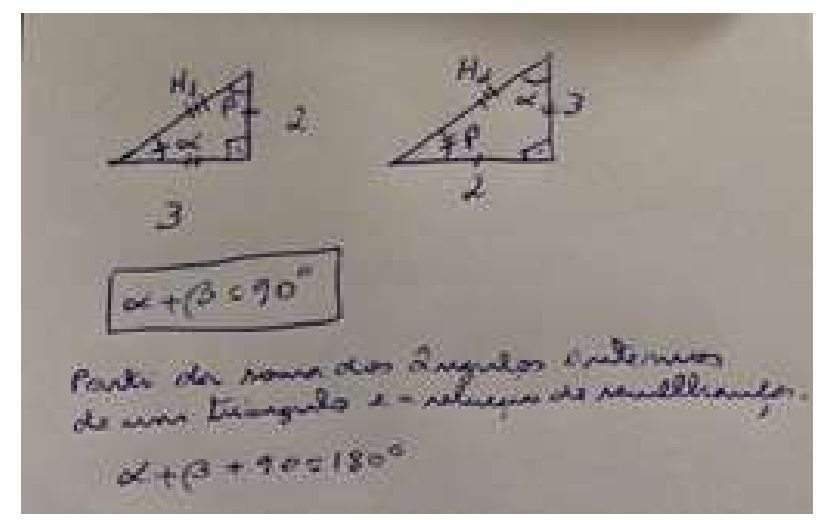

Fonte: arquivo do pesquisador

G: não entregou, justificando não ter conseguido visualizar a resposta.

A análise das respostas mostra dois aspectos: o primeiro diz respeito ao envolvimento de imagens visuais (apenas cinco minutos para visualizar a imagem apresentada); o segundo está relacionado ao 


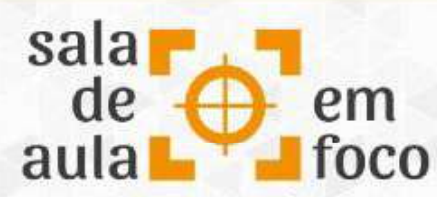

- REVISTA ELETRÔNICA -

ISSN 2316-7297

não emprego de métodos algébricos e/ou raciocínio utilizados na resolução do problema de modo correto (PRESMEG, 1986). Possivelmente, esse problema apresentado em uma aula de trigonometria ou geometria plana, recorrendo a fórmulas prévias, poderia produzir outros resultados, o que não corrobora com as pesquisas do autor do artigo de priorizar métodos visuais na resolução de problemas matemáticos.

\section{2 - A SEGUNDA TAREFA}

A segunda tarefa também foi adaptada do Canguru Matemático sem Fronteiras, ano 2019, porém agora na Categoria Estudante, destinada a alunos do $12^{\circ}$ ano de escolaridade. Foi orientado que lessem o enunciado da Figura 05 durante dois minutos e, em seguida, foi projetada a figura do enunciado e recomendado que a visualizassem e guardassem na memória suas características durante mais três minutos. Após, retirou-se a imagem e projetou-se as cinco alternativas para escolherem uma única e a justificar, posteriormente, encaminhando ao líder do grupo.

Figura 05 -slide correspondente à tarefa 2

2. Três peças triangulares estão ligadas como se indica na figura díreita. Qual das seguintes figuras mostra essas três peças triangulares ligadas da mesma forma?

(A)

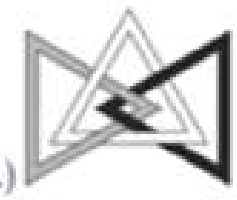

(B)

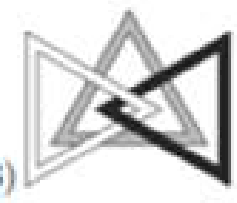

(C)

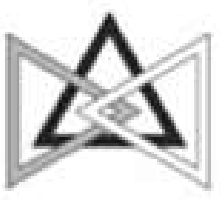

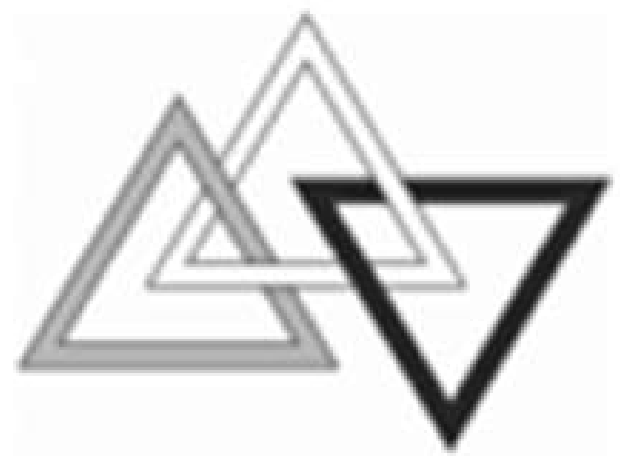

(D)

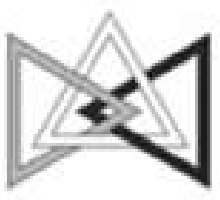

(E)

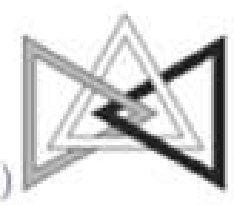

Fonte: adaptado do Canguru Matemático de 2019 


\section{sala \\ de $\theta$ em \\ aula foco}

Desta feita, A C, D, F e G responderam imediatamente, enquanto B e E não participaram dessa jornada. A resposta correta para este item é a da letra (D). No que segue, apresenta-se as alternativas

A: escolheu corretamente o item (D), fotografando e encaminhando ao professor rapidamente pelo WhatsApp e, posteriormente, fez a seguinte justificativa: "Acredito que a D seja a correta pois os triângulos cinza e preto não se ligam e eles passam pelo branco uma vez por cima de uma aresta, e outra por baixo".

C: respondeu corretamente e sua justificativa foi por meio do esquema constante da Figura 06.

Figura 06 -Escolha e justificativa do estudante $C$

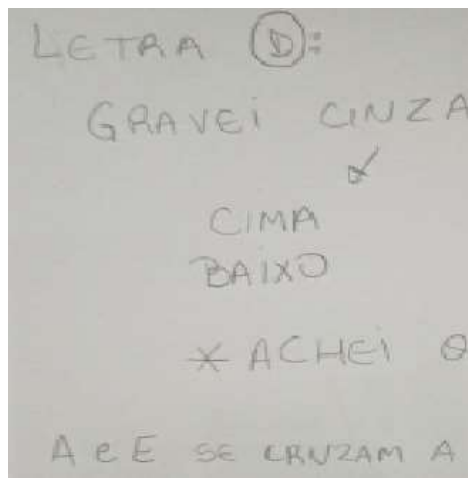

Fonte: arquivo do pesquisador

F: escolheu corretamente como os anteriores e justificou: "oi, penso que é a letra $D$, pois nesse caso a cinza e a branca se entrelaçam, e a cinza e a preta não se entrelaçam, como lembro do desenho original".

Os outros dois não acertaram suas escolhas, sendo que,

D: respondeu que a correta seria a letra (C) e justificou (Figura 07).

\section{Figura 07 -Escolha e justificativa do estudante D}

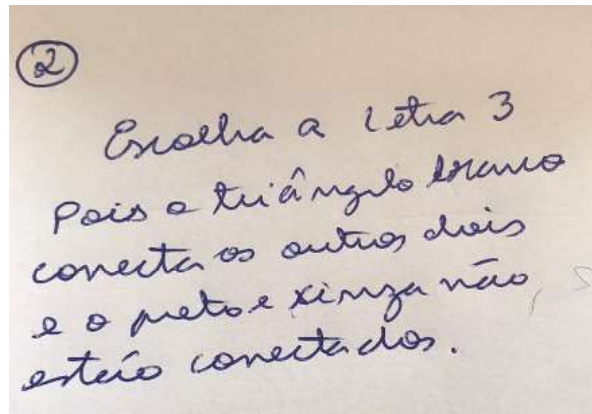

Fonte: arquivo do pesquisador 


\section{sala \\ de \\ aula

G: respondeu a letra (E) dizendo: "acho que é, mas não sei justificar.

Foi concluído, da análise feita, que três dos cinco respondentes acertaram corretamente tal questão, pois, diferentemente da anterior, não exigia conhecimentos matemáticos prévios para a resolução. Portanto, os aspectos visuais se fizeram fortemente presentes na atividade, o que ampara o dito por Guzmán (1997) sobre a forma explícita como são expressas as representações. Por sua vez, o fato de explorarem a memória visual para a escolha da resposta adequada vai ao encontro do que esse autor caracteriza como visualizar, ou seja, formular imagens mentais para o desenvolvimento do processo de abstração. Assim, acredita-se que a tarefa vem ao encontro das pesquisas do autor sobre o tema.

\section{3 - A TERCEIRA TAREFA}

Na terceira semana consecutiva dos encontros, esta questão foi proposta do mesmo site do qual foram adaptadas as anteriores, porém correspondente à Categoria Cadete, destinada a alunos do 9o ano de escolaridade e aplicada no ano 2019.

A tarefa, novamente, buscava analisar a criatividade e a imaginação dos participantes e, desta feita, somente o indivíduo C não estava presente (Figura 8). O professor apresentou, leu o problema juntamente com os participantes e deu as instruções de como deveriam proceder para apresentar a solução. O tempo de duração foi menor do que os anteriores, para evitar que pudessem explorar recurso didático, uma vez que o desejado era o construto mental dos indivíduos.

\section{Figura 08 -Tarefa 3}

\section{A Cátia dobrou uma folha de papel quadrada exatamente ao meio duas vezes \\ e, em seguida, cortou-a ao meio duas vezes, como indicado na figura. Quantos dos pedaços de papel, obtidos após os cortes, têm a forma de quadrados?}

Tente visualizar EM SUA MENTE, por 1 minuto antes de eu apresentar a figura. Deixe seu whats posicionado para me responder INDIVIDUALMENTE, em mais 2 minutos.

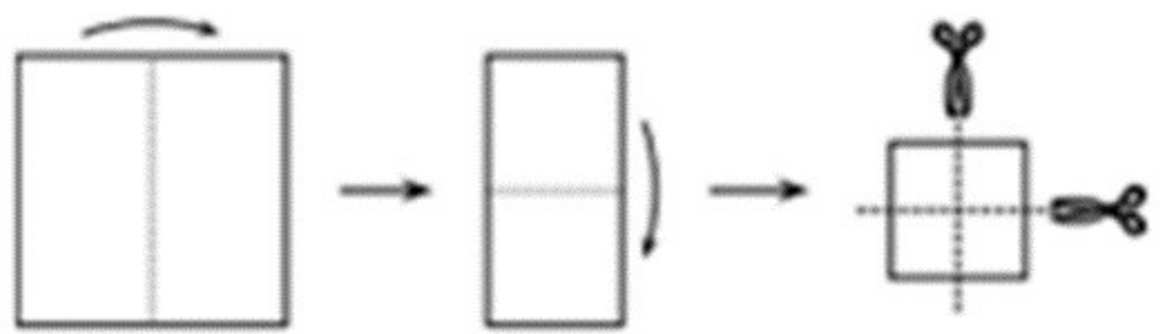

Fonte: Adaptada do Canguru Matemático, 9a ano 


\title{
sala \\ de $\oplus$ em \\ aula foco
}

-REVISTA ELETRÔNICA

Na sequência, analisa-se as respostas dos indivíduos: A, E. F e G que responderam serem quatro quadrados; D respondeu que eram cinco (o único a fornecer a resposta correta); enquanto B respondeu que eram oito. As justificativas apresentadas foram as seguintes:

D: Rta: 5. "Eu imaginei a montagem mentalmente e depois que fiz os dois cortes tentei desmontar mentalmente a figura, foi aí que cheguei nos 5 quadrados e 4 retângulos".

Posteriormente, foi solicitada uma justificativa do procedimento que utilizou para fornecer resposta correta, ao que o indivíduo respondeu:

\begin{abstract}
Inicialmente, fiz as dobras mentalmente, imaginado como ficaria. Depois fiz o corte com a tesoura e separei mentalmente. Após essa etapa desdobrei mentalmente cada parte. Restaram 5 quadrados (um maior e 4 menores de mesmo tamanho) e 4 retângulos de mesmo tamanho. $\mathrm{O}$ quadrado maior foi o que se originou do vértice esquerdo superior e os outros 4 do vértice inferior direito. Os 4 retângulos se originaram 2 em cada um dos vértices restantes. (Estudante D)
\end{abstract}

A justificativa mostra um potencial deste indivíduo em construtos mentais, especialmente ao dizer, cortei com a tesoura (mentalmente) e desdobrei mentalmente, ou seja, vai ao encontro do que Leivas (2009) define como visualização (grifo do autor).

A: Rta: 4. "Na primeira ideia, imaginei as dobras do papel no sentido horizontal sempre e, após o corte do mesmo, pensei que geraram 4 quadrados. Entretanto, pensando novamente, fiquei um pouco em dúvida porque dobrar ao meio na segunda vez não necessariamente poderia gerar quadrados, porque se dobrasse ao meio no sentido vertical, geraria apenas 4 retângulos. Ao dobrar no sentido horizontal, se formam 4 quadrados".

B: Rta: 8. "Retângulos".

E: Rta: 4. "Explicação da atividade: Ao dobrar uma folha com forma quadrada ao meio, ela fica com formato retangular, sendo o lado maior o dobro do menor. Ao dobrar novamente ao meio (em relação ao lado maior), a folha volta a ficar com formato quadrado. Ao recortar a folha nas marcas de dobra, ficamos com quatro pedaços, de formato quadrado".

F: Rta: 4. "se é que entendi... eu considerei a figura apresentada, mas não sei se fiz os cortes corretos, pois não dizia cortar ao meio...". 


\section{sala \\ de $\oplus$ - em \\ aula foco}

- REVISTA ELETRÔNICA

\section{G: Rta: 4. Não justificou}

A análise das respostas dos indivíduos investigados mostrou dificuldades com a imaginação e, até mesmo, com a criatividade na resolução do problema com apenas recursos visuais. Talvez por estarem acostumados a usarem recursos concretos, muitas vezes, os estudantes não buscam construtos mentais, e articulam com possíveis soluções sem o contato direto com eles, apenas buscando mentalmente o que poderia produzir a solução de um problema. Entende-se que a imaginação é muito útil na resolução de problemas, como indicado por Hadamard (2000), especialmente quando não há determinado um conteúdo explícito ao qual se refere e, assim, é necessário buscar na mente alternativas criativas para levantar hipóteses e realizar deduções.

Portanto, os aspectos almejados com esta terceira tarefa deixaram a desejar. Porém, algo curioso pôde ser constatado: o estudante D não havia acertado nenhuma das duas tarefas anteriores e, nesta, foi o único a desempenhá-la corretamente.

Na sequência do artigo, aborda-se sobre o feedback das soluções dos problemas.

\section{4 - UM FEEDBACK SOBRE AS TAREFAS}

Após a segunda tarefa foi feito um feedback a respeito das duas primeiras e, após a terceira, no próximo encontro, o da última. Sobre seu papel na educação, Beviláqua et al. (2020, p. 58) afirmam que "[...] O feedback pode ser, ainda hoje, um fenômeno inerente ao que se entende por papel do docente e, por conseguinte, um fenômeno que se dá de forma mais prática que teórica [...]". A partir dessa concepção e da importância educacional de retomar o que já foi feito, julgou-se oportuno discutir soluções apresentadas pelos participantes de modo a chegar ao consenso correto das mesmas.

Inicialmente, retomou-se a Tarefa 1 e discutiu-se com os participantes sobre suas soluções para o problema, solicitando ao estudante A que esclarecesse sua forma correta de percebê-lo. Nesse momento, os demais manifestaram surpresa por não terem percebido o fato tão relevante e explorado que é a congruência de triângulos, estudada no final do Ensino Fundamental e utilizada com frequência no transcorrer da formação matemática. Por sua vez, indicaram também que o fato de terem um tempo limitado para pensar e responder pode ter sido o fator que levou aos erros cometidos. 


\section{sala \\ de $\oplus$ em \\ aula foco}

O líder do grupo e organizador da investigação apresentou a solução em forma de construção em software de Geometria Dinâmica (Figura 9).

Figura 09 -Solução da Tarefa 1

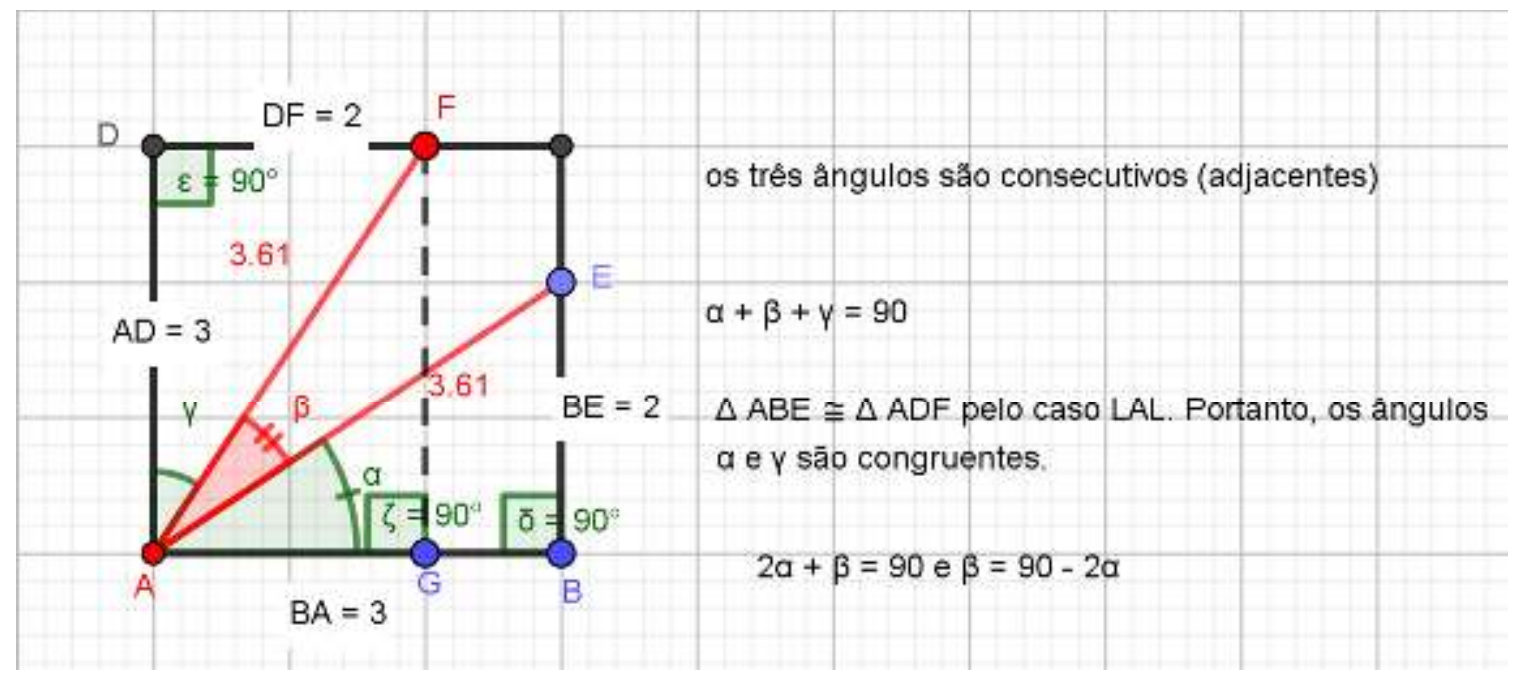

Fonte: construção do autor.

Foi também retomada a solução inconclusiva apresentada por $E$, ou seja, evidenciando $\alpha=\operatorname{arc} \operatorname{tg}(2 / 3)$ e $\beta=\operatorname{arc~tg}(5 / 12)$, corretamente. Entretanto, pelo tempo disponibilizado para fornecer as respostas, faltou a criatividade e a imaginação de buscar na própria calculadora do celular quais seriam os ângulos correspondentes e, possivelmente, encontrar a relação entre os dois, como solicitado.

Em relação à segunda tarefa, não havia muito o que esclarecer, uma vez que o visual forneceria completamente a possibilidade de escolha da alternativa correta. Destaca-se, entretanto, o esquema organizado pelo estudante C, o qual forneceu uma boa concepção organizacional de justificar um pensamento para resolução de um problema eminentemente visual. Como um dos objetivos do grupo é elaboração de recursos didáticos, o investigador apresentou uma sequência que poderia ser feita em uma aula presencial com estudantes da escola básica, ou mesmo de licenciatura ou ação continuada. Em virtude do isolamento social, os recursos materiais como compasso e esquadros estavam no gabinete do investigador na Universidade, de modo que soluções criativas foram propostas. Assim, ele aproveitou faixas de $11 \mathrm{~cm}$ de largura que dispunha, em três cores distintas. Para melhor aproveitamento do material, buscou a construção de triângulos equiláteros com esta 


\section{sala \\ de \\ aula

dimensão para a altura. A partir disso, obteve a dimensão do lado e fez a respectiva construção. Como figuras geométricas planas estão apenas na mente, não sendo materializadas, a fim de associar os entes geométricos à questão, construiu pequenas faixas internas, de modo a poder recortá-las pelas linhas internas paralelas aos lados do triângulo representado. Posteriormente, destacou a região triangular interna (Figura 10).

\section{Figura 10 -Triângulos e regiões triangulares equiláteros}
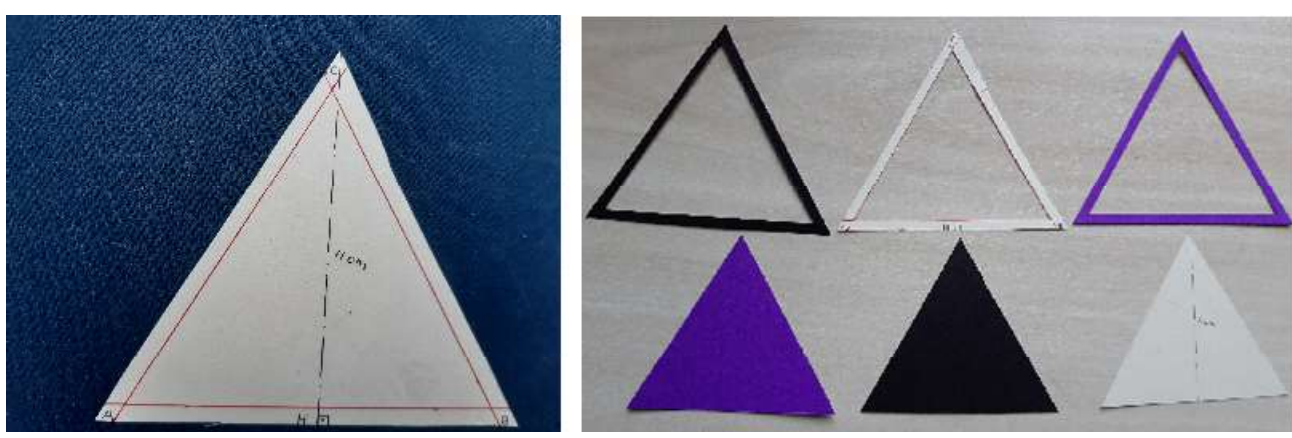

Fonte: construção do autor.

Com um corte na região triangular branca, o investigador introduziu os outros dois objetos de modo a que ilustrassem o que fora apresentado na Tarefa e voltou a conectar os três juntos (Figura 11). Com isso, o manuseio proporciona uma exploração concreta para a obtenção da resposta correta.

Figura 11 -Representação em material concreto da Tarefa 2

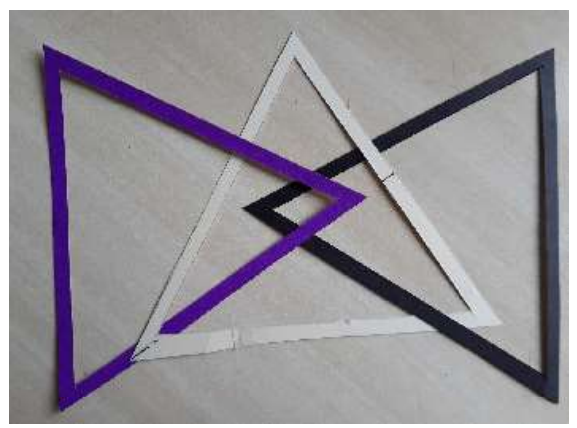

Fonte: construção do autor.

Dessa construção, pode-se perceber o quanto é importante o conhecimento matemático voltado para resolver problemas concretos que surgem para o indivíduo. Não basta, por exemplo, ter a fórmula que relacione a medida da altura de um triângulo equilátero com a de seu lado, quando não se sabe fazer a transposição conveniente para cada momento. A isso, reporta-se a Chevallard (1991) sobre o 


\section{sala \\ de $\theta$ em \\ aula foco}

REVISTA ELETRÔNICA

significado da transposição didática: "Todo projeto social de ensino e de aprendizagem se constitui dialeticamente com a identificação e a designação de conteúdos de saberes como conteúdos a ensinar" (p. 45). No entender do autor do artigo, há falta de levar, didaticamente, o conteúdo do matemático, especialmente, para o que é desenvolvido na formação de professores de Matemática a fim de proporcionar opções para sua prática profissional.

A respeito da terceira tarefa, a resposta pode ser facilmente obtida com recurso básico papel, dobras e tesoura, como se pode observar na Figura 12 em que as flechas indicam o sentido das dobras.

Figura 12 -Dobrando e recortando quadrado

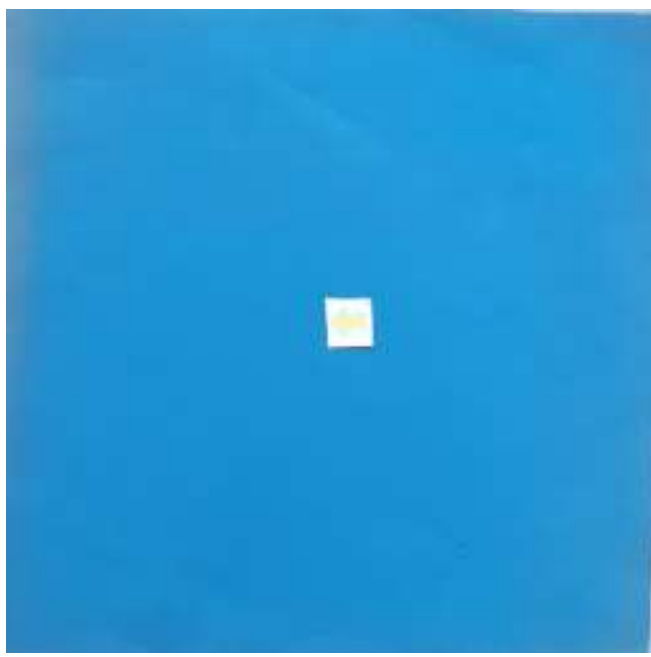

(a)

(b)

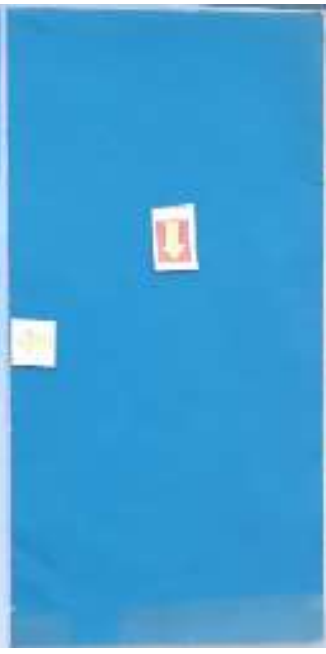

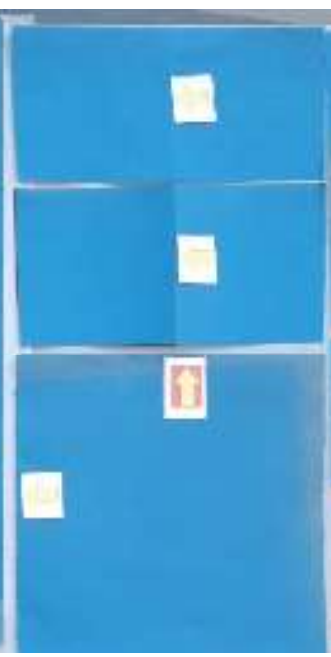

(c)

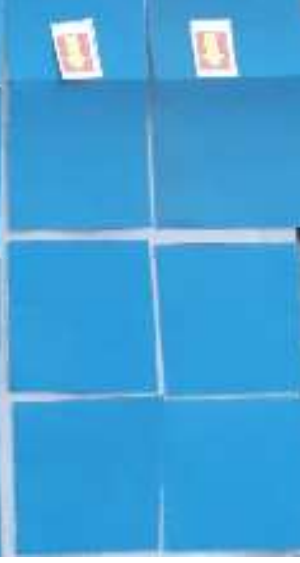

(d)

Fonte: construção do autor

Partindo-se da região quadrada da esquerda (a) e dobrando-se da esquerda para a direita, como indicado no problema, a linha de dobra (b) (esquerda) não será recortada. Em seguida, ao dobrar de cima para baixo (c) a parte dobrada, a linha superior também não será cortada e a parte lateral esquerda superior irá sobrepor-se à anterior. Portanto, as duas continuarão com o mesmo comprimento do lado do quadrado maior, porém com largura sendo a metade deste lado. Assim, ao recordar, serão obtidas quatro regiões retangulares com estas duas dimensões (d): uma igual à medida do lado do quadrado e a outra, a metade dessa medida. Por sua vez, o canto inferior esquerdo contém quatro sobreposições da folha, e recortando nos dois lados internos, o corte produzirá quatro regiões quadradas idênticas. 


\section{sala \\ de $\oplus$ em \\ aula foco}

-REVISTA ELETRÔNICA

Por fim, o canto superior esquerdo também contém quatro sobreposições, porém, a parte superior direita se mantém intacta. Ao desdobrá-la origina-se uma região quadrangular equivalente às quatro anteriores juntas, com área igual à metade da original. Conclui-se que ficarão cinco regiões quadradas e quatro retangulares destacados no total.

Embora se considere que este é um problema criativo de Geometria, como os indicados por Conway, Gilman e Thurston (2010), ele apresenta um grau de compreensão bem maior do que os anteriores, por necessitar da visualização como construto mental apurado, no sentido apontado por Leivas (2009). No entanto, acredita-se que tais habilidades podem e devem ser estimuladas na formação inicial do professor de Matemática, bem como na de docentes atuando nos Anos Iniciais. Dessa forma, desenvolve-se pensamento geométrico nos indivíduos e estimula-se a investigações curiosas dos estudantes.

\section{5 - CONSIDERAÇÕES}

Neste artigo, apresentou-se uma investigação geométrica que teve por objetivo analisar como participantes de um grupo de estudos e pesquisas em Geometria exploram a visualização, a imaginação e a criatividade em atividades geométricas. Foi envolvido pensamento visual em três encontros do grupo durante o período de pandemia, os quais foram realizados a distância, virtualmente, em que se verificou como os indivíduos participantes utilizam a visualização para resolver questões geométricas em aula virtual.

A experiência mostrou que é possível realizar atividades de pesquisa online e ilustrou sugestões de que essas podem ser exploradas com estudantes de diversos níveis de escolaridade, uma vez que as questões foram retiradas do concurso português Canguru Matemático. Todas as questões foram adaptadas da prova de 2019, sendo a primeira aplicada a alunos de 10 e 11 anos, a segunda para os de $12^{\circ}$ grau de escolaridade e a terceira para os de 90 grau.

Percebeu-se que o tema continua sendo relevante para pesquisas, como foi apontado pelo Working Group do PME, que trata de Representação e Visualização, assunto que tem sido objeto de estudo do GEPGEO. Dessa forma, tem-se, pelos resultados obtidos envolvendo estudantes de diversos níveis 


\section{sala \\ de $\oplus$ em \\ aula foco}

REVISTA ELETRÔNICA

de escolaridade, que atividades desse gênero devem continuar a ser empregadas, produzindo novas pesquisas. Além disso, tais atividades podem servir para orientar professores a incluí-las nos currículos escolares ou, ao menos, em suas práticas cotidianas de sala de aula.

Ao finalizar essas considerações a respeito da experiência investigativa, reitera-se o indicado por Hadamard (2000, p. 104), sobre o que levou Descartes a afirmar que "[...] a imaginação será muito útil, sobretudo, quando se tiver de resolver um problema não por simples dedução, mas por várias deduções sem ligação entre si, das quais, a seguir, será preciso fazer a enumeração completa e coordenar os resultados". Além disso, invocando-se também os efeitos psicológico da imaginação e da criatividade, julga-se oportuno o recomendado por Vygotsky (2014), de que combinados exigem liberdade de pensar, agir e conhecer, a fim de dominar pensamento e conceitos.

Acredita-se que o descrito e analisado neste artigo possa contribuir com professores de sala de aula e, talvez, estimular novas pesquisas.

\section{REFERÊNCIAS}

BEVILÁQUA, André Firpo; COSTA, Alan Ricardo; FIALHO, Vanessa Ribas; LEFFA, Vilson José. Um olhar complexo sobre o feedback e a formação de professores a distância. Polifonia, Cuiabá-MT, v. 26, n.44, p. 57-80, out.-dez., 2019.

CHEVALLARD, Yves. La transposición didáctica: del saber sabio al saber ensinado. Trad. Claudia Gilman. Argentina: Aique Grupo Editor S.A., 1991.

CIFUENTES, José Carlos. Uma via estética de acesso ao conhecimento matemático. Boletim GEPEM. Rio de Janeiro, n. 46, p. 55-72, 2005.

CONWAY, John; DOYLE, Peter; GILMAN, Jane; THURSTON, Bill. Geometria e Imaginação. Versão 0.941, Winter 2010. Publicado on-line:19 dez 2014.

GUZMÁN, Miguel de. Enseñanza de la matemática. In: GIL PÉREZ, D.; OZÁMIZ, M. G. Enseñanza de las ciencias y la matemática: tendencias e innovaciones. 1993. Biblioteca Virtual OEI. p. 62-89. Disponível em: <http://www.oei.org.co/oeivirt/ciencias.pdf >. Acesso em 03 nov. 2007.

HADAMARD, Jacques. Psicologia da invenção na matemática. Trad. Estela dos Santos Abreu. Rio de Janeiro: Contraponto Editora Ltda., 2009.

LEIVAS, J.C.P. Imaginação, intuição e visualização: a riqueza de possibilidades da abordagem geométrica no currículo de cursos de licenciatura em Matemática. Tese (Doutorado em EducaçãoMatemática). Universidade Federal do Paraná. Curitiba, 2009, 294p. 


\section{sala \\ de $\oplus$ em \\ aula foco}

MIKUSKA, Márcia Inês Schabarum. UMA ANÁLISE DO ENSINO DA GEOMETRIA NO CURSO DE FORMAÇÃO DE DOCENTES DO ENSINO FUNDAMENTAL. X CONGRESSO NACIONAL DE EDUCAÇÃOEDUCERE. CURITIBA, UFPR.Acesso em 12 maio 2020. Anais..., 2011.

OLIVEIRA, Sabrine Costa. (Re) Construção do pensamento geométrico de professores sobre transformações geométricas. Dissertação (mestrado) - Instituto Federal do Espírito Santo, Programa de Pós-graduação em Educação em Ciências e Matemática, Vitória, 2016.

PAVANELLO, Regina Maria. O abandono de ensino de geometria: uma visão histórica. 1989. 196f. Dissertação (mestrado) - Universidade Estadual de Campinas, Faculdade de Educação, Campinas, SP. Disponível em: <http://www.repositorio.unicamp.br/handle/REPOSIP/252057>. Acesso em: 14 jul. 2018.

PRESMEG, Norma C. Visualization and mathematical giftedness. Educational Studies in Mathematics, v. 17, n. 3, p. 297-311, 1986.

SEVERINO, A.J. Metodologia do trabalho científico. 24. ed. Revista e atualizada. São Paulo: Cortez, 2016.

SOARES, G. de O.; VARGAS, A. F.; LEIVAS, J.C.P. PERCEPÇÕES E SENTIMENTOS DE ALUNOS DO ENSINO MÉDIO EM RELAÇÃO À MATEMÁTICA. Boletim Cearense de Educação e História da Matemática- Volume 07, Número 19, 05 - 23 (2020)

VYGOTSKY, L.S . Imagination and creativity of the adolescente. Psicologia Soviética. Volume 28. Edição 1. 1990. Disponivel em <https://www.tandfonline.com/doi/abs/10.2753/RPO10610405290173>; Acesso em 13 maio 2020. 